\title{
The Effect of Prepregnancy Body Mass Index and Gestational Weight Gain on Birth Weight
}

\author{
Hiroko Watanabe \\ Department of Clinical Nursing, Shiga University of Medical Science \\ Japan
}

\section{Introduction}

Birth weight is an important predictor in infant mortality and morbidity, growth, development and wellbeing in adult life (Goldfrey \& Barker, 2000). Reduced-size-at-birth infants, which include low birth weight (LBW: birth weight $<2,500 \mathrm{~g}$ ) and small-forgestational age (SGA: below the 10th percentile for gestational age) infants, are at greater risk of having reduced educational capacity, school performance, and intellectual development than are infants of normal birth weight (Lagerstrom et al., 1991).

Some adult health risks also have a clear negative correlation with infant birth weight. In 1980 ', Barker \& Osmond in the UK reported that differences around the UK in neonatal mortality as maker for LBW in 1921-1925 predicted death rates from stroke and heart disease in 1968-1978 (Barker \& Osmond, 1986). They found that LBW and weight at one year were associated with an increased risk of death from cardiovascular disease. There was an approximate two times of the mortality rate from the highest to the lowest extremes of birth weight (Barker et al., 1989).

Over recent decades, accumulating evidence around the world has suggested that LBW may be associated with an increased risk of subsequent development of a variety of complications in adulthood including cardiovascular disease, non-insulin-dependent diabetes mellitus, hypertension, and dyslipidemia (Li et al., 1998; Rich-Edwards et al., 1999). These studies have led to discoveries of the developmental, fetal origins of adult health and disease; fetal programming theory states that fetal growth restriction, secondary to under nutrition, has long-lasting physiologic and structural effects that predispose the fetus to diseases later in life.

On the other hand, high birth weight relates to complications during delivery including shoulder dystocia and caesarean sections and to obesity during child- and adulthood (Stotland et al., 2004; Weiss et al., 2004). Increased numbers of high birth weight infants $(>4,000 \mathrm{~g})$ and large-for-gestational age infants (LGA; birth weight above the 90th percentile for gestational age) have been reported in North America and Europe (Kramer et al., 2002; Surkan et al., 2004). In the past three decades, there has been a $116 \mathrm{~g}$ increase in singleton birth weight (Catalano, 2007). Fetal growth is affected by maternal obesity and by mothers being overweight during pregnancy. Recent evidence suggests that LGA infants are also at increased risk for childhood and subsequent adult obesity as well as type two diabetes (Parsons et al., 2001). Thus, birth weight may be an important parameter of adult disease. 
Numerous factors are associated with birth weight, such as parity and the sex of the child (Bonellie et al., 2008), maternal and gestational diabetes (Langer et al., 2005), maternal smoking during pregnancy (Ward et al., 2007), maternal overweight status (Larsen et al., 1990), and gestational weight gain (GWG) (Kiel et al., 2007). Of these factors, previous studies have suggested particularly that both prepregnancy body mass index (BMI; weight $(\mathrm{kg}) /$ height $\left.(\mathrm{m})^{2}\right)$ and GWG are positively associated with birth weight in the offspring and are related to risks of both low and high offspring birth weight (Brown et al., 2002; Rode et al., 2007). Women with a normal prepregnancy BMI and those who meet the recommended weight gains are healthiest and have healthier children. Adequate GWG contributes to better pregnancy outcomes in both mothers and infants, for short- and long-term health. Prepregnancy BMI and GWG management may be a key factor influencing the health of women during pregnancy and the development of the fetus. This review focuses on the effect of prepregnancy BMI and adequate GWG on birth weight.

\section{Optimal birth weight for low neonatal mortality rate}

Birth weight is the single strongest predictor of infant survival. One determinant of birth weight is gestational age: as the fetus matures, it grows. The other determinant is gestational age, because birth weight is a summary of fetal growth. Susser et al. (1972) reported that when gestational age and weight are analyzed simultaneously, birth weight accounts for $90 \%$ of the variance of perinatal mortality, whereas gestational age accounts for barely $5 \%$. On the other hand, Wilcox \& Skjaerven (1992) stated that an infant benefits as much from an increase in gestational age as from an increase in its weight, relative to the weights of others at the same gestational age.

Birth weight between the 10th and 90th percentile has been generally accepted as appropriate fetal growth and classified as an appropriate gestational age (AGA) infant. However, what birth weight range in single term infants is optimal to reduce the neonatal mortality rate? National weight-for-gestational-age charts are created from the weight distributions of livebirths at each age using population-based data from each country. According to Japanese Vital Statistics, the lowest early neonatal mortality rate per 1000 live births in 2005 was 0.3 for infants weighing 3,000-3,999 g. The rate increased with decreasing birth weight: 0.4 for 2,500-2,999 g, 1.7 for 2,000-2,499 $\mathrm{g}$ and 10.9 for 1,500-1,999 $\mathrm{g}$ (Ministry of Health, Labour and Welfare, Japan, 2006).

The National Center for Health Statistics in the United States reported similar findings for the year 1995-2002, using singletons data (Joseph et al., 2009). For centuries, gestational maturity has been understood as important to infant survival. Research establishing an association between birth weight and neonatal morbidity/ mortality rates in term livebirth infants is limited. Joseph et al. (2009) show the birth weight-specific rates of serious neonatal morbidity and neonatal mortality in 17,554,934 livebirths from perinatal mortality data files of the National Center for Health Statistics for the years 1995-2002. All were singleton livebirths with a clinical estimate of gestation between 36 and 42 weeks born to white or black mothers in the United States (Figure 1). Based on empirical observation, birth weightspecific patterns of serious neonatal morbidity or neonatal death follow a specific pattern, that is, that neonatal morbidity/mortality rates decrease exponentially with increasing birth weight in the LBW range. This declining pattern changes to a flat, stable rate at "optimal" birth weight before serious neonatal morbidity/neonatal mortality rates increase with 
increasing birth weight. In the regression model, the low optimal birth weight at 40 weeks' gestation was 2,982 $\mathrm{g}$ (95\% confidence interval (CI): 2,965-2,999 g) for females and 3,012 $\mathrm{g}$ (95\% CI: 3,008-3,018 g) for males. Similarly, the high end of optimal birth weight range was 3,813 g (95\% CI: 3,774-3,852 g) for females and 3,978 g (95\% CI: 3,976-3,980 g) for males.

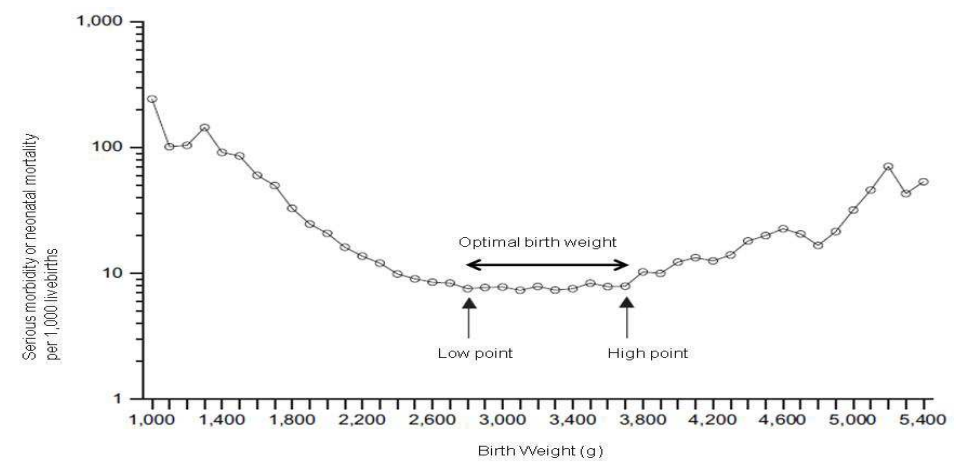

Source; Reference [Joseph KS., et al.,2009]

Fig. 1. Birth weight specific rates of serious neonatal morbidity and neonatal mortality at 37 weeks' gestational age among singletons

The optimal birth weight range may vary according to the age, race, ethnicity, and size of the mother, as maternal growth constraint may protect the health of the mother and baby. A study of 16.4 million women using the National Center for Health Statistics' 1983-1987 national lived birth/infant death data sets, examined the association between birth weight and neonatal mortality rate in adolescent (aged 15-18 years) and adult mothers (aged 19-34 years) of black and white race. Minimum neonatal mortality rates occurred at the same birth weight $(3,500$ to $4,499 \mathrm{~g}$ white and 3,000 to 3,999 g black) whether mothers of the infants were adolescents or adults. The most favorable range of birth weight, in which survival was greatest, commenced at 3,000 g for all mothers and terminated at 3,999 $\mathrm{g}$ for most black adolescents and black adults, at 4,499 $\mathrm{g}$ for most white adolescents, and at 4,999 $\mathrm{g}$ for white adults. Of infants born to mothers < or $=16$ years old, $33 \%$ were lighter and $1.5 \%$ were heavier than the favorable birth weight range (Rees et al., 1996). Assisting mothers to bear infants with birth weight in the optimal weight range corresponding with low neonatal mortality in each country is an appropriate goal of clinical management.

\section{Optimal weight gain recommendation}

Adequate weight gain by prepregnancy BMI is important for optimal pregnancy outcomes. The Institute of Medicine (IOM) released new gestational weight guidelines (IOM, 2009) to reinforce those released in 1990 (IOM, 1990), because many key aspects of the health of women of childbearing age have changed, such as the increasingly high rates of overweight and obese women, increasing GWG, and the increasing age of women becoming pregnant. There are several salient differences. First, the new guidelines change the BMI categories to those commonly used for other adult health outcomes. Second, they provide a closed gestational weight gain range for obese women, based on data from women with BMI values of $30-34.9 \mathrm{~kg} / \mathrm{m}^{2}$. 
According to the new guideline, underweight women $\left(\mathrm{BMI}<18.5 \mathrm{~kg} / \mathrm{m}^{2}\right)$ should gain 12.5 $18.0 \mathrm{~kg}$ during pregnancy, normal weight women (BMI $18.5-24.9 \mathrm{~kg} / \mathrm{m}^{2}$ ) should gain $11.5-$ $16.0 \mathrm{~kg}$, and overweight women (BMI $25.0-29.9 \mathrm{~kg} / \mathrm{m}^{2}$ ) should gain $7.0-11.5 \mathrm{~kg}$. This is the standard for weight gain worldwide (IOM, 2009) (Table 1). This guideline will be used in clinical practice as an effective weight management tool, and it will help to evaluate the association between these gestational weight ranges and pregnancy outcomes worldwide. Weight gain within the guidelines has been associated with healthy fetal and maternal outcomes.

\begin{tabular}{|c|c|c|c|c|}
\hline \multirow{4}{*}{ Prepregnancy BMI $\left(\mathrm{kg} / \mathrm{m}^{2}\right)$} & \multirow{2}{*}{\multicolumn{2}{|c|}{ Total Weight Gain }} & \multirow{2}{*}{\multicolumn{2}{|c|}{$\begin{array}{l}\text { Rates of Weight Gains } \\
2^{\text {nd }} \text { and } 3^{\text {rd }} \text { Trimester }\end{array}$}} \\
\hline & & & & \\
\hline & \multirow{2}{*}{ Range in kg } & \multirow{2}{*}{ Range in lbs } & Mean (range) in & Mean (range) in \\
\hline & & & $\mathrm{kg} /$ week & lbs/week \\
\hline Underweight & $12.5-18$ & $28-40$ & 0.51 & 1 \\
\hline$(<18.5)$ & & & $(0.44-0.58)$ & $(1-1.3)$ \\
\hline Normal weight & $11.5-16$ & $25-35$ & 0.42 & 1 \\
\hline$(18.5-24.9)$ & & & $(0.35-0.5)$ & $(0.8-1)$ \\
\hline Overweight & $7-11.5$ & $15-25$ & 0.28 & 0.6 \\
\hline$(25.0-29.9)$ & & & $(0.23-0.33)$ & $(0.5-0.7)$ \\
\hline Obese & $5-9$ & $11-20$ & 0.22 & 0.5 \\
\hline$(\geq 30.0)$ & & & $(0.17-0.27)$ & $(0.4-0.6)$ \\
\hline
\end{tabular}

* Calculations assume a 0.5-2 kg (1.1-4.4 lbs) weight gain in the first trimester

Source; Reference [Institute of Medicine, 2009]

Table 1. 2009 IOM recommendations for total and rate of weight gain during pregnancy by prepregnancy BMI

In the 1990 IOM guideline, two thirds of women exceeded the recommended weight gain (Schieve et al., 1998). In a study of over 4,000 women from the University of California's San Francisco Perinatal Database, 23\% of underweight women, $49 \%$ of normal-weight women, and $70 \%$ of overweight women exceeded the 1990 IOM recommendations (Carmichael et al., 1997). On the other hand, newly released, 2009 IOM recommendations were assessed by Park et al. (2011) in a population-based, retrospective cohort study of 570,672 women with singleton, full-term livebirths in Florida from 2004 to 2007. They found that $31.6 \%$ of underweight women, $42.8 \%$ of normal-weight women, and $65.0 \%$ of overweight women exceeded the 2009 IOM recommendations. These results suggest that interventions including nutritional education and behavioral strategies to promote healthy and appropriate weight gain during pregnancy should approach obese women in particular.

\section{Trends of reproductive age-women's body composition}

\subsection{The prevalence of overweight or obese women}

Maternal size before conception plays a key role in determining pregnancy outcomes. BMI is an appropriate indicator of prepregnancy nutrition when assessed in women who are well- 
nourished (Saldana et al., 2004). Overweight status and obesity have become serious global public health issues. Nearly two thirds of reproductive-aged women in the United States are currently overweight or obese $\left(\geq 25 \mathrm{~kg} / \mathrm{m}^{2}\right)$. In the National Health and Nutrition Examination Survey (NHANES), the prevalence of obesity (BMI $\geq 30 \mathrm{~kg} / \mathrm{m}^{2}$ ) in women aged 20-49 years continues to be high, exceeding 30\% after 1999 (Flegal et al., 2010)(Fig. 2).

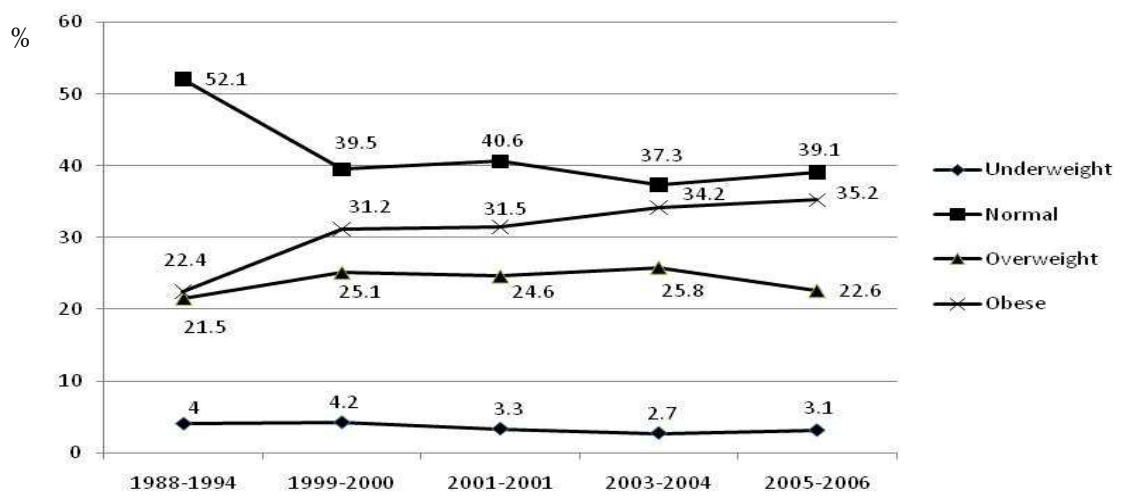

BMI categories $\left(\mathrm{kg} / \mathrm{m}^{2}\right)$; Underweight, <18.5; Normal, 18.5-24.9; Overweight, 25.0-29.9; Obese, 230.0.

Fig. 2. Trends of underweight, normal, overweight, and obese among U.S. women aged 20-40 y

In the latest NHANES data from 2007-2008 of 877 women aged 20-39 years, the prevalence of overweight status (BMI $\geq 25 \mathrm{~kg} / \mathrm{m}^{2}$ ) and obesity were $59.5 \%$ and $34.0 \%$, respectively. Trends are similar by age. The prevalence in all classes of obesity [(class I $\left(30-34.9 \mathrm{~kg} / \mathrm{m}^{2}\right)$, class II $\left(35-39.9 \mathrm{~kg} / \mathrm{m}^{2}\right)$, and class III $\left.\left(\geq 40 \mathrm{~kg} / \mathrm{m}^{2}\right)\right)$ ] is lowest in white, non-Hispanic women, and highest in non-Hispanic black women in the United States (Flegal et al., 2010). Other developed countries have observed similar trends. In Australia in 2007-2008, 44.5\% women aged 25-34 years and 55.3\% women aged 35-44 years were overweight or obese, which constituted a marked increase over the previous 20 years (Australian Institute of Health and Welfare, 2010). In the UK, more than $50 \%$ of women in the reproductive age category of 25-44 years are overweight or obese. There has been a $69 \%$ increase in maternal obesity from 1990 to 2004, a period of only 15 years (Heslehurst et al., 2007). Thus, the increased number of overweight and obese reproductive-aged women is a worldwide phenomenon.

\subsection{The prevalence of underweight women}

The prevalence of underweight status $\left(\mathrm{BMI}<18.5 \mathrm{~kg} / \mathrm{m}^{2}\right)$ was only $3.1 \%$ of reproductiveaged women in 2005-2006 (Flegal et al., 2010). Underdeveloped regions, such as South Asia or Africa, where undernutrition is generally highest, or there are socio-economic characteristics or food poverty, report the highest prevalence of underweight women (Macro International Inc, 2007). However, even some developed countries such as Japan show high prevalence rates. Over the last two decades in Japan, the prevalence of underweight women has increased from $19.6 \%$ to $21.2 \%$ in those aged $20-29$ years, and from $8.6 \%$ to $13.3 \%$ in those aged $30-39$ (Hayashi et al., 2006). A low body mass index in highly 
industrialized countries is not, in all probability, a result of environmental factors such as periodic food shortages and malnutrition; therefore, one must consider it an expression of constitutional low weight or a result of cosmetically induced starvation. Excessive thinness has been glamorized among reproductive aged women, and unhealthy dieting to lose weight has become a popular practice in that age group. Body image in younger women is susceptible to societal influence through mass media, such as television, movies, and magazines.

\section{Influence of prepregnant BMI and GWG on birth weight}

\subsection{SGA infant}

Low prepregnancy BMI and low GWG have been associated with the delivery of smaller infants. There is strong evidence for an association between weight gains below the IOM guidelines and the risk of having an SGA infant ( Nielsen et al., 2006; Park et al., 2011). In a study undertaken of 26,028 women in California, those with gestational weight gains below the IOM guidelines had a significantly higher risk of SGA infants when compared with women with a weight gain above IOM guidelines, adjusting for prepregnancy BMI (Park et al., 2011).

Similar results were also observed in a study among Swedish women with singleton fullterm births. The risks for SGA were higher when gaining $<8 \mathrm{~kg}(95 \% \mathrm{CI}: 1.68-2.35)$ and lower when gaining $>16 \mathrm{~kg}$ (95\% CI: 0.50-0.61) (Cedergren, 2006). Merchant et al. (1999) reported lower mean birth weights of newborns among Pakistani women with prepregnancy BMI $<19 \mathrm{~kg} / \mathrm{m}^{2}$ who gained $>12.5 \mathrm{~kg}$ compared to those who gained $12.5 \mathrm{~kg}$. Women in the lowest quartile for both prepregnancy BMI and GWG were 5.6 times more likely to have intrauterine growth restriction (IUGR) infants, compared to women in the upper quartile (Naidu \& Rao, 1994). The research among 3,071 Japanese women who gave birth to single-term infants found that underweight women were 1.7 times and 1.5 times more likely to give birth to a SGA or LBW infant, respectively (Watanabe et al., 2007). However, an increase in GWG eliminated or reduced the incidence of SGA.

Current evidence indicates that GWG, particularly during the second and third trimesters, is an important determinant of fetal growth (Althuizen et al., 2006; Kaiser et al., 2008). Inadequate weight gain during these trimesters is associated with an increased risk of LBW or IUGR. Health care providers should give women individual graphs of their weight gains at each antenatal check up, having viewed valuable sources of information on diet and nutrition.

\subsection{LGA infant}

The mean birth weight has continuously increased in United States, Canada, Europe, and Asia (Kramer et al., 2002). In Australia, LGA births have increased from 9.2\% to $10.8 \%$ in male infants and from $9.1 \%$ to $11 \%$ in female infants from 1990 to 2005 (Hadfield et al., 2009). The $25 \%$ to $36 \%$ increase in maternal BMI over the past decade has translated to approximately a $25 \%$ increase in the incidence of newborns with high birth weight (Surkan et al., 2004). The possible reason may be increased maternal body weight and/or excess weight gain during pregnancy beyond the recommended IOM guideline. Strong evidence confirms the association between excessive GWG and increased birth weight in all BMI categories. 
A population-based retrospective cohort study was reported of 570,672 women aged 18-40 years, examining the association between the 2009 IOM recommendations and adverse infant outcomes by prepregnancy BMI reported that fifty-one percent of women were above the IOM guidelines. Gains of greater than the recommended amount were associated with increased odds of LGA (95\% CI: 1.27-5.99), and gains less than those recommended were associated with decreased odds of LGA (95\% CI: 0.27-0.77) (Park et al., 2011). Similar findings observed that the proportions of LGA increased with high prepregnancy BMI, but the proportions of SGA decreased. Obese women with lower weight gain or weight loss during pregnancy had lower risk of LGA and higher risk of SGA (Nohr et al., 2008).

\section{Long-term effects of fetal environment for offspring}

Many animal models have demonstrated that altering the environment in utero leads to lifelong consequences, such as high blood pressure (Mamun et al, 2009), impaired glucose tolerance (Fraser et al., 2010), insulin resistance (Ozanne \& Hales, 1999), and altered hepatic architecture and function (Ozanne et al., 2001). Population-based prospective cohort studies starting from different geographical regions in the preconception period or in early fetal life and following the offspring from early fetal life until young adulthood seem to be the most suitable epidemiological design (Geelhoed \& Jaddoe, 2010; Jaddoe \& Witteman, 2006) (Fig. 3).

There is now increasing evidence supporting the effect of the in utero environment on the development of obesity and risk factors for adult diseases (Ong, 2006; Pettitt \& Jovanovic, 2007). Epidemiological studies confirm that the relationships between human birth weight and adult obesity, hypertension, or insulin resistance are U-shaped curves rather than inverse linear associations over a full range of birth weight distributions (Barker, 1998) (Fig. 4). That is, children born at both the lower - classified as SGA - and the upper - classified as LGA - ends of the birth weight spectrum are at risk of obesity and, subsequently, a range of adult diseases in later life.

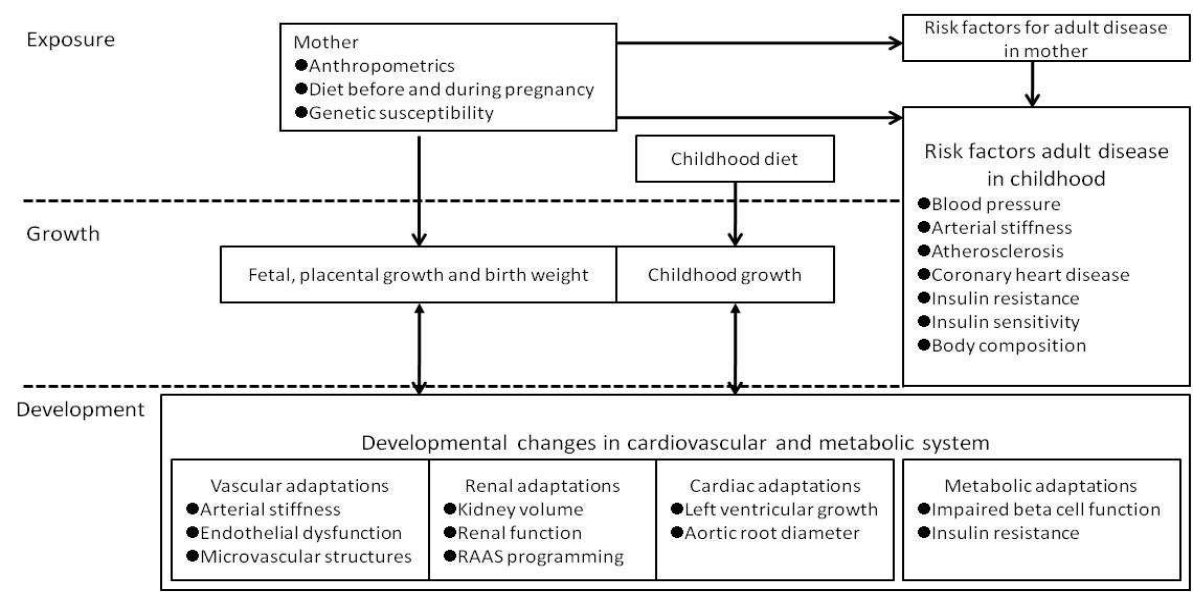

Source; Reference [Geelhoed \& Jaddoe, 2010; Jaddoe \& Witteman, 2006]

Fig. 3. Models for studying the fetal origins of adult diseases hypotheses in epidemiological studies. 


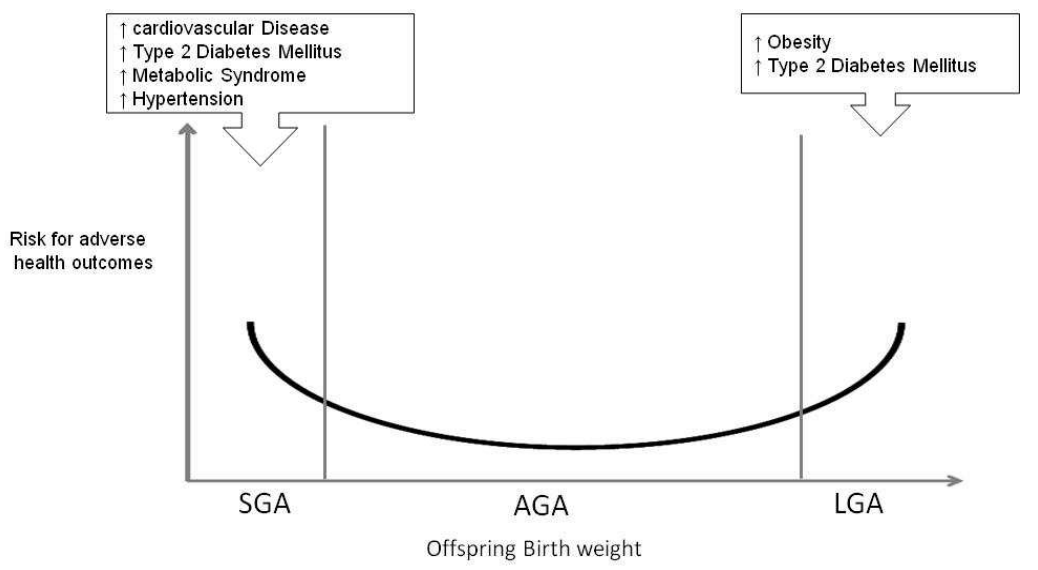

Source; Reference [Barker DJ, 1998]

Fig. 4. Hypothesized U-shaped relationship between offspring birth weight and risk for postnatal adverse health outcomes

\subsection{The consequence of being SGA}

LBW and SGA infants are at risk for hypertension, cardiovascular disease, insulin resistance, and diabetes mellitus type 2 in adult life (Saenger, 2007). A recent systematic review of the literature relating to the birth weight/type 2 diabetes relationship noted that for every one$\mathrm{kg}$ increase in weight at birth, the risk of diabetes in adulthood decreased by $25 \%$ (OR 0.75 , 95\% CI: 0.70-0.81) (Whincup et al., 2008). In an Indian study of young adults, which followed up at birth and every six months until the age of 21 years, plasma glucose concentrations and insulin resistance were inversely related to birth weight, and impaired glucose tolerance and diabetes were associated with lower weight and BMI at the age of 1 year, after adjusting for adult BMI (Bhargava et al., 2004).

Studies linking birth weight to kidney disease and hypertension in adulthood have also been reported. LBW infants have lower kidney weight with a decreased number of nephrons, which indicates that hypertensive patients have lower nephron numbers (Hughson et al., 2003). A histomorphometric study observed a 13\% decrease of nephron number in LBW infants (Manalich et al., 2000). Schmidt et al. (2005) investigated kidney length or volume in early life in SGA infants compared to AGA infants. They found that being SGA was associated with small kidneys at birth and impaired kidney growth in early childhood. Hotoura et al. (2005) compared SGA infants with a gestational age of 31 to 36 weeks with a control group of AGA infants. They reported that SGA infants had shorter kidney length at birth compared with AGA infants. Similar findings were observed in the SGA term infant, but the association disappeared in later childhood (Giapros et al., 2006).

In addition, a recent study reported that SGA was associated with adult psychological disorders. Children born full term but weighing 2,475 g had increased psychological distress in later life, and a 1SD decrease in birth weight for gestational age was associated with increased psychological distress in adulthood ( Wiles et al., 2005). 


\subsection{The consequence of being LGA}

High birth weight and LGA infants are prone to induce neonatal complications (Das \& Sysyn, 2004) and to developing insulin resistance (Giapros et al., 2007), obesity, and diabetes in later life (Boney et al., 2005; Dietz, 2004). LGA infants have increased fat mass at birth compared with AGA infants (Armitage et al., 2008). McCance et al. (1994) examined birth weight and diabetes in later life among Pima Indians. Diabetes rates among persons with high birth weight $(\geq 4500 \mathrm{~g})$ were almost twice as high as among those with a birth weight between 2,500 and 4,500 g. Similar findings were observed in a meta-analysis where infants with high birth weight (>4,000 g) had 1.36 times higher (95\%CI: 1.07-1.73) incidence of type 2 diabetes in later life than normal birth weight $(2,500-4,000 \mathrm{~g})$ infants did.

Furthermore, a recent study has shown that obese women have a high risk for gestational diabetes mellitus, providing a future risk for type 2 diabetes mellitus (Catalano et al., 2009). Diabetes in pregnancy that results in high birth weight and early onset of diabetes in the offspring represents a vicious cycle (Knowler et al, 1990), with the offspring of women who had diabetes during pregnancy being very likely to have already developed diabetes by the time they reach their childbearing years. Boney et al. (2005) conducted a longitudinal cohort study to determine whether children who were LGA at birth and offspring of mothers with or without gestational diabetes mellitus were at increased risk for developing the metabolic syndrome in childhood at age 6 to 11 years. They found that children who were LGA at birth and exposed to an intrauterine environment of either diabetes or maternal obesity were at increased risk of developing metabolic syndromes.

\section{Conclusion}

Birth weight is an important predictor in infant mortality and morbidity, growth, development, and wellbeing in adult life. Women with a normal prepregnancy BMI and within the adequate range of GWG associated with minimal risk for SGA and LGA have better pregnancy outcomes in both mothers and infants, for short- and long-term health. However, nearly two thirds of reproductive-aged women are currently overweight or obese. On the other hand, the number of women with BMI below 18.5 has increased in some countries. In addition, only $28 \%$ of women actually adhere to the guidelines for optimum birth weight; over half gain in excess of the recommended weight gain.

Prepregnancy BMI and pregnancy weight gain reflect maternal nutritional status before and during pregnancy; this status plays a crucial role in creating an optimal intrauterine environment. Understanding the relationship between maternal nutrition and birth outcomes may provide a basis for developing nutritional interventions that will improve birth outcomes and long-term quality of life. All women of reproductive age should be encouraged to follow the government recommendations and eat a well-balanced diet. A critical goal for women is to make behavior changes to achieve good nutritional status before, during, and after conception, which may lead to improved birth outcomes.

\section{References}

Althuizen, E.; van Poppel, M.N.; Seidell, J.C.; van der Wijden, C. \& van Mechelen, W. (2006). Design of the New Life (style) study: a randomized controlled trial to optimize maternal weight development during pregnancy. BMJ Public Health, Vol. 6: 168. 
Armitage, J.A.; Poston, L. \& Taylor, P.D. (2008). Developmental origins of obesity and the metabolic syndrome: the role of maternal obesity. Front Horm Res, Vol. 36: 73-84.

Australian Institute of Health and Welfare (AIHW). (2010). Australia's health 2010: The eighth biannual health report of the AIHW. Australian Institute of Health and Welfare, Canberra.

Barker, D.J. \& Osmond, C. (1986). Infant mortality childhood nutrition, and ischaemic heart disease in England and Wales. Lancet, Vol. 1(8489): 1077-81.

Barker, D.J.; Winter, P.D.; Osmond, C.; Margetts, B, \& Simmonds SJ. (1989). Weight in infancy and death from ischaemic heart disease. Lancet, Vol. 2(8663): 577-80.

Barker, D.J. (1998). In utero programming of chronic disease. Clin Sci, Vol. 95(2): 115-28.

Bhargava, S.K.; Sachdev, H.S.; Fall, C.H.; Osmond, C.; Lakshmy, R.; Barker, D.J.; Biswas, S.K.; Ramji, S.; Prabhakaran, D. \& Reddy, K.S. (2004) Relation of serial changes in childhood body mass index to impaired glucose tolerance in young adulthood. $N$ Eng J Med, Vol. 350(9): 865-75.

Bonellie, S.; Chalmers, J.; Gray, R.; Greer, I.; Jarvis, S. \& Williams, C. (2008). Centile charts for birthweight for gestational age for Scottish singleton births. BMC Pregnancy Childbirth, Vol. 8: 5.

Boney, C.M.; Verma, A.; Tucker, R. \& Vohr, B.R. (2005). Metabolic syndrome in childhood: association with birth weight, maternal obesity, and gestational diabetes mellitus. Pediatrics, Vol. 115(3), pp. e290-6.

Brown, J.E.; Murtaugh, M.A.; Jacobs, D.R. Jr. \& Margellos, H.C. (2002). Variation in newborn size according to pregnancy weight change by trimester. Am J Clin Nutr, Vol. 76(1): 205-9.

Carmichael, S., Abrams, B. \& Selvin, S. (1997). The pattern of maternal weight gain in women with good pregnancy outcomes. Am J Public Health, Vol. 87(12): 1984-8.

Catalano, P.M. (2007). Management of obesity in pregnancy. Obstet Gynecol, Vol. 109(2 Pt 1): 419-33.

Catalano, P.M.; Presley, L.; Minium, J.; Hauguel-de Mouzon, S. (2009). Fetuses of obese Mothers develop insulin resistance in utero. Diabetes Care, Vol. 32(6): 1076-80.

Cedergren, M. (2006). Effects of gestational weight gain and body mass index on obstetrics outcome in Sweden. Int J Gynaecol Obstet, Vol. 93(3): 269-74.

Das, U.G. \& Sysyn, G.D. (2004). Abnormal growth: intrauterine growth retardation, small for gestational age, large for gestational age. Pediatr Clin N Am, Vol. 51(3): 639-54.

Demographic and Health Surveys, Macro International Inc, Access on June 1, 2011, http://www.measuredhs.com/countries/

Dietz, W.H. (2004). Overweight in childhood and adolescence. $N$ Engl J Med, Vol. 350(9): 855-7.

Flegal, K.M.; Carroll, M.D.; Ogden, C.L. \& Curtin, L.R. (2010). Prevalence and trends in obesity among US adults, 1999-2008. JAMA, Vol. 303(3): 235-41.

Fraser, A.; Tilling, K.; Macdonald-Wallis, C.; Sattar, N.; Brion, M.J.; Benfield, L.; Ness, A.; Deanfield, J.; Hingorani, A.; Nelson, S.M.; Smith, G.D. \& Lawlor, D.A. (2010). Association of maternal weight gain in pregnancy with offspring obesity and metabolic and vascular traits in childhood. Circulation, Vol. 121(23): 2557-64.

Geelhoed, J.J. \& Jaddoe, V.W. (2010). Early influences on cardiovascular and renal development. Eur J Epidemiol, Vol. 25(10): 677-92. 
Giapros, V.; Drougia, A.; hotoura, E.; Papadopoulou. F.; Argyropoulou, M. \& Andronikou, S. (2006). Kidney growth in small-for-gestational-age infants: Evidence of early accelerated renal growth. Nephrol Dial Transplant, Vol. 21(12): 422-7.

Giapros, V.; Evagelidou, E.; Challa. A.; Kiortsis, D.; Drougia. A. \& Andronikou, S. (2007). Serum adiponectin and leptin levels and insulin resistance in children born large for gestational age are affected by the degree of overweight. Cli Endocrinology 2, Vol. 66(3): 353-9.

Goldfrey, K.M. \& Barker, D.J. (2000). Fetal nutrition and adult disease. Am J Clin Nutr, Vol. 71 (5 Suppl), pp.1344S-52S.

Hadfield, R.M.; Lain, S.J.; Simpson, J.M.; Ford, J.B.; Raynes-Greenow, C.H.; Morris, J.M. \& Roberts, C.L. (2009). Are babies getting bigger? An analysis of birthweight trends in New South Wales, 1990-2005. Med J Aust, 190(6): 312-5.

Hayashi, F.; Takimoto, H.; Yoshita, K. \& Yoshiike, N. (2006). Perceived body size and desire for thinness of young Japanese women: a population-based survey. Br J Nutr, Vol. 96(6): 1154-62.

Heslehurst, N.; Ells, L.J.; Simpson, H.; Batterham, A.; Wilkinson, J. \& Summerbell, C.D. (2007). Trends in maternal obesity incidence rates, demographic predictors, and health inequalities in 36,821 women over a 15-year period. BJOG, Vol. 114(2): 18794.

Hotoura, E.; Argyropoulou, M.; Papadopoulou, F.; Giapros, V.; Drougia, A.; Nikolopoulos, P. \& Andronikou, S. (2005). Kidney development in the first year of life in smallfor-gestational-age preterm infants. Pediatr Radiol, Vol. 35(10): 991-4.

Hughson, M.; Farris, A.B.; Douglas-Denton, R.; Hoy, W.E. \& Bertram, J.F. (2003). Glomerular number and size in autopsy kidneys: the relationship to birth weight, Kidney Int, Vol. 63(6): 2113-22.

Institute of Medicine. (1990). Nutrition during pregnancy: part I, weight gain; part $\alpha$, nutrient supplements. National Academies Press, Washington, DC.

Institute of Medicine. (2009). Weight gain during pregnancy: reexamining the guidelines. National Academies Press, Washington, DC.

Jaddoe, V.W. \& Witteman, J.C. (2006). Hypotheses on the fetal origins of adult diseases: contributions of epidemiological studies. Eur J Epidemiol, Vol. 21(2): 91-102.

Joseph, K.S.; Fahey, J.; Platt, R.W.; Liston, R.M.; Lee, S.K.; Sauve, R.; Liu, S.; Allen, A.C. \& Kramer, M.S. (2009). An outcome-based approach for the creation of fetal growth standards: do singletons and twins need separate standards? Am J Epidemiol, Vol. 169(5): 616-24.

Kaiser, L.; Allen, L.H. \& American Diabetic Association. (2008). Position of the American Dietic Association: nutrition and lifestyle for a healthy pregnancy outcome. J Am Diet Assoc, Vol. 108(3): 553-61.

Kiel, D.W.; Dodson, E.A.; Artal, R.; Boehmer, T.K. \& Leet, T.L. (2007). Gestational weight gain and pregnancy outcomes in obese women: how much is enough?. Obstet Gynecol, Vol. 110(4): 752-8.

Knowler, W.C.; Pettitt, D.J.; Saad, M.F. \& Bennett, P.H. (1990). Diabetets mellitus in the Pima Indians: incidence, risk factors and pathogenesis. Diabetes Metab Rev, Vol. 6(1): 1-27.

Kramer, M.S.; Morin, I.; Yang, H.; Platt, R.W.; Usher, R.; McNamara, H.; Joseph, K.S. \& Wen, S.W. (2002). Why are babies getting bigger? Temporal trends in fetal growth and its determinants. J Pediatr, Vol. 141(4): 538-542. 
Lagerstrom, M.; Bremme, K,; Eneroth, P. \& Magnusson, D. (1991). School performance and IQ-test scores at age 13 as related to birth weight and gestational age. Scand J Psychol, Vol. 32 (4): 316 - 24.

Langer, O.; Yogev, Y.; Most, O. \& Xenakis, E.M. (2005). Gestational diabetes: the consequences of not treating. Am J Obstet Gynecol, Vol. 192(4): 989-97.

Larsen, C.E.; Serdula, M.K. \& Sullivan, K.M. (1990). Macrosomia: influence of maternal overweight among a low-income population. Am J Obstet Gynecol, Vol.162(2), pp. 490-4.

Li, R.; Haas, J.D. \& Habicht, J.P. (1998). Timing of the influence of maternal nutritional status during pregnancy on fetal growth. Am J Hum Biol. Vol. 10: 529-39.

McCance, D.R.; Pettitt, D.J.; Hanson, R.L.; Jacobsson, L.Y.; Knowler, W.C. \& Bennett, P.H. (1994). Birth weight and non-insulin-dependent diabetes: thrifty fenotype, thrifty phenotype, or surviving small baby genotype? BMJ, Vol. 308(6934): 942-5.

Mamun, A.A.; O'Callaghan, M.; Callaway, Williams, G.; Najman, J. \& Lawlor, D.A. (2009). Associations of gestational weight gain with offspring body mass index and blood pressure at 21 years of age: evidence from a birth cohort study. Circulation, Vol. 119(13): 1720-7.

Manalich, R.; Reyes, L.; Herrera, M.; Melendi, C. \& Fundoral, I. (2000). Relationship between weight at birth and the number and size of renal glomeruli in humans; A histomorhometric study. Kidney Int, Vol. 58(2): 770-3.

Merchant, S.S.; Momin, I.A.; Sewani, A.A. \& Zuberi, N.F. (1999). Effect of prepregnancy body mass index and gestational weight gain on birth weight. J Pak Med Assoc, Vol. 49(1): 23-5.

Ministry of Health, Labour and Welfare, Japan, Mothers' \& Children's Health Division. (2006). Maternal and Child Health Statistics of Japan, Mothers' \& Children's Health Organization, Tokyo (in Japanese).

Naidu, A.N. \& Rao, N.P. (1994). Body mass index: a measure of the nutritional status in Indian populations. Eur J Clin Nutr, Vol. 48 (Suppl 3): S131-40.

Nielsen, J.N.; O'Brien, K.O.; Witter, F.R.; Chang, S.C.; Mancini, J.; Nathanson, M.S. \& Caufield, L.E. (2006). High gestational weight gain does not improve birth weight in a cohort of African American adolescents. Am J ClinNutr, Vol. 84(1): 183-9.

Nohr, E.A.; Vaeth, M.; Barker, J.L.; Sorensen, T. \& Olsen, J. (2008). Rasmussen KM. Combined associations of prepregnancy body mass index and gestational weight gain with the outcome of pregnancy. Am J Clin Nutr, Vol. 87(6): 1750-9.

Ong, K.K. (2006). Size at birth, postnatal growth and risk of obesity, Horm Res, Vol. 65 (Suppl 3): 65-9.

Ozanne, S.E. \& Hales, C.N. (1999). The log-term consequences of intrauterine protein malnutrition for glucose metabolism. Proc Nutr Soc, Vol. 58: 615-9.

Ozanne, S.E.; Dorling, M.W.; Wang, C.L. \& Nave, B.T. (2001). Impaired PI 3-Kinase activation in adipocytes from early growth-restricted rats. Am J Physiol, Vol. 280(3): E534-9.

Park, S.; Sappenfield, W.M.; Bish, C.; Salihu, H.; Goodman, D. \& Bensyl, D. (2011). Assessment of the institute of medicine recommendations for weight gain during pregnancy: Florida, 2004-2007. Matern Child Health J, Vol. 15(3): 289-301. 
Parsons, T.J.; Power, C. \& Manor, O. (2001). Fetal and early life growth and body mass index from birth to early adulthood in 1958 British cohort: longitudinal study. BMJ, Vol. 323(7325): 1331-5.

Rees, J.M.; Lederman, S.A. \& kiely, J.L. (1996). Birth weight associated with lowest neonatal mortality: infants of adolescent and adult mothers. Pediatrics, Vol. 98(6 Pt 1): 1161-6.

Pettitt, D.J. \& Jovanovic, L. (2007). Low birth weight as a risk factor for gestational diabetes, diabetes, and impaired glucose tolerance during pregnancy. Diabetes Care, Vol. 30 (Suppl 2): S147-9.

Rich-Edwards, J.W,; Colditz, G.A.; Stampfer, M.J.; Willett, W.C.; Gillman, M.W.; Hennekens, C.H.; Speizer, F.E. \& Manson, J.E. (1999). Birthweight and the risk for type 2 diabetes mellitus in adult women. Ann Intern Med,Vol. 130(4 Pt 1): 278 - 84 .

Rode, L.; Hegaard, H.K.; Kjaergaard, H.; Moller, L.F.; Tabor, A. \& Ottesen, B. (2007). Association between maternal weight gain and birth weight. Obstet Gynecol, Vol. 109(6): 1309-15.

Saenger, P.; Czernichow, P.; Hughes, I. \& Reiter, E.O. (2007). Small for gestational age: short stature and beyond. Endocr Rev, Vol. 28(2): 219-51.

Saldana, T.M.; Siega-Riz, A.M. \& Adair, L.S. (2004). Effect of macronutrient intake on the development of glucose intolerance during pregnancy. Am J Clin Nutr, Vol. 79(3): 479-86.

Schieve, L.A.; Cogswell, M.E. \& Scanlon, K.S. (1998). Trends in pregnancy weight gain within and outside ranges recommended by the Institute of Medicine in a WIC population. Matern Child Health J, Vol. 2(2): 111-6.

Schmidt, I.M.; Chellakooty, M.; Biosen, K.A.; Damgaard, I.N.; Mau Kai, C.; Olgaard, K. \& Main, K.M. (2005). Impired kidney growth in low-birth-weight children: Distinct effects of maturity and weight for gestational age. Kidney Int, Vol. 68(2): 731-40.

Stotland, N.E.; Caughey, A.B.; Breed, E.M. \& Escobar, G.J. (2004). Risk factors and obstetric complications associated with macrosomia. Int J Gynaecol Obstet, Vol. 87(3): 220-6.

Surkan, P.J.; Hsieh, C.C.; Johansson, A.L.; Dickman, P.W. \& Cnattingius, S. (2004). Reasons for increasing trends in large for gestational age births. Obstet Gynecol, Vol. 104(4): $720-6$.

Susser, M.; Marolla, F.A. \& Fleiss, J. (1972). Birth weight, fetal age and perinatal mortality. Am J Epidemiol, Vol. 96(3): 197-204.

Ward, C.; Lewis, S. \& Coleman, T. (2007). Prevalence of maternal smoking and environmental tobacco smoke exposure during pregnancy and impact on birth weight: restrospective study using Millennium Cohort. BMC Public Health, Vol. 7: 81.

Watanabe, H.; Fukuoka, H.; Inoue, K.; Koyasu, M.; Nagai, Y. \& Takimoto, H. (2007). Restricting weight gain during pregnancy in Japan: a controversial factor in reducing perinatal complications. Eur J Obstet Gynecol Reprod Biol, Vol. 133(1): 53-9.

Weiss, J.L.; Malone, F.D.; Emig, D.; Ball, R.H.; Nyberg, D.A.; Comstock, C.H.; Saade, G.; Eddleman, K.; Carter, S.M.; Craigo, S.D.; Carr, S.R. \& D'Alton, A.E. (2004). Obesity, obstetric complications and cesarean delivery rate-a population-based screening study. Am J Obstet Gynecol, Vol. 190(4): 1091-7.

Whincup, P.H.; Kaye, S.J.; Owen, C.G. \& Anazawa, S. (2008). Birth weight and risk of type 2 diabetes: a systematic review. JAMA, Vol.300(24): 2886-97. 
Wilcox, A.J. \& Skjaerven, R. (1992). Birth weight and perinatal mortality: the effect of gestational age. Am J Public Health, Vol. 82(3): 378-382.

Wiles, N.J.; Peters, T.J.; Leon, D.A. \& Lewis, G. (2005). Birth weight and psychological distress at age 45-51 years: Results from the Aberdeen Children of the 1950s cohort study. Br J Psychiatry, Vol. 187: 21-8. 


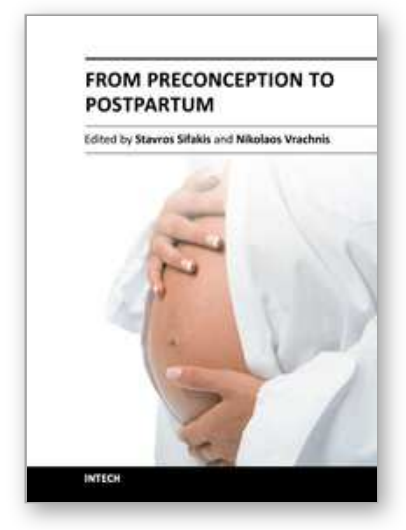

\author{
From Preconception to Postpartum \\ Edited by Dr. Stavros Sifakis
}

ISBN 978-953-51-0353-0

Hard cover, 314 pages

Publisher InTech

Published online 23, March, 2012

Published in print edition March, 2012

Obstetrics is evolving rapidly and finds itself today at the forefront of numerous developments. Providing selected updates on contemporary issues of basic research and clinical practice, as well as dealing with preconception, pregnancy, labor and postpartum, the present book guides the reader through the tough and complex decisions in the clinical management. Furthermore, it deepens the scientific understanding in the pathogenetic mechanisms implicated in pregnancy and motivates further research by providing evidence of the current knowledge and future perspectives in this field. Written by an international panel of distinguished authors who have produced stimulating articles, the multidisciplinary readers will find this book a valuable tool in the understanding of the maternal, placental and fetal interactions which are crucial for a successful pregnancy outcome.

\title{
How to reference
}

In order to correctly reference this scholarly work, feel free to copy and paste the following:

Hiroko Watanabe (2012). The Effect of Prepregnancy Body Mass Index and Gestational Weight Gain on Birth Weight, From Preconception to Postpartum, Dr. Stavros Sifakis (Ed.), ISBN: 978-953-51-0353-0, InTech, Available from: http://www.intechopen.com/books/from-preconception-to-postpartum/the-effect-ofprepregnancy-body-mass-index-and-gestational-weight-gain-on-birth-weight-

\section{INTECH}

open science | open minds

\author{
InTech Europe \\ University Campus STeP Ri \\ Slavka Krautzeka 83/A \\ 51000 Rijeka, Croatia \\ Phone: +385 (51) 770447 \\ Fax: +385 (51) 686166 \\ www.intechopen.com
}

\author{
InTech China \\ Unit 405, Office Block, Hotel Equatorial Shanghai \\ No.65, Yan An Road (West), Shanghai, 200040, China \\ 中国上海市延安西路65号上海国际贵都大饭店办公楼 405 单元 \\ Phone: +86-21-62489820 \\ Fax: +86-21-62489821
}


(C) 2012 The Author(s). Licensee IntechOpen. This is an open access article distributed under the terms of the Creative Commons Attribution 3.0 License, which permits unrestricted use, distribution, and reproduction in any medium, provided the original work is properly cited. 